\title{
Choosing the right sling for your patient
}

\author{
Stephen S. Steele, MD'; Gregory G. Bailly ${ }^{2}$ \\ 'Queen's University, Kingston, ON; 2 Department of Urology, Dalhousie University, Halifax, NS; Canada
}

Cite as: Can Urol Assoc J 2017;11 (6Suppl2):S132-4. http://dx.doi.org/10.5489/cuaj.4635

\section{Abstract}

Recent data has demonstrated a one in five lifetime risk of a woman requiring stress urinary incontinence (SUI) surgery. Currently, most women opt for a synthetic midurethral sling (MUS), with over 3.6 million placed worldwide. This article attempts to identify whether a gold standard exists with regards to surgical correction of female SUI.

When considering which sling type to use for which incontinent woman, the published data demonstrates excellent results for both synthetic mesh (retropubic or transobturator routes) and fascial pubovaginal slings for most patients. Intrinsic sphincter deficiency does appear to be better treated with the use of a retropubic approach, although still with less than stellar results. With little to differentiate, the treatment of most female SUI may be solely based on which sling the surgeon feels most comfortable performing. Currently, most urologists and gynecologists favour synthetic MUS over fascial slings in surgical-naïve patients; however, recent U.S Food and Drug Administration (FDA) warnings concerning the use of mesh in transvaginal surgery have patients questioning the safety of synthetic MUS for the treatment of SUI.

\section{Introduction}

The prevalence of stress urinary incontinence (SUI) is somewhat difficult to establish, as it tends to depend on the definition employed in published literature; ${ }^{1}$ however, recent data has demonstrated an almost one in five lifetime risk of a woman requiring SUI surgery. ${ }^{2}$

In the past, retropubic colposuspensions and pubovaginal slings (PVS) with autologous fascia were the primary surgical modalities used to treat SUI; however, over the last 20 years, far fewer of both procedures have been performed, as the therapeutic technology for treating SUI has advanced to include synthetic material. ${ }^{3}$ Specifically, with the implementation of transvaginal synthetic mesh in the 1990s, the pendulum has swung quickly away from colposuspensions and heavily towards synthetic midurethral slings (MUS). In fact, between 2005 and 2013, there were over 3.6 million
MUS placed worldwide for the treatment of SUI in women. ${ }^{3}$ Many would consider the synthetic MUS to be the gold standard surgical option for SUI.

As time has passed, the procedure and technology have advanced to the point where there are several synthetic and non-synthetic sling options for the treatment of SUI, including the retropubic and transobturator routes, transvaginal and fascial slings. The purpose of this article is to explore whether one sling type has established itself as the gold standard and what factors may play into the success or failure of one particular sling modality.

\section{Short- and long-term outcomes}

It has been well-documented in many studies that there is no statistically significant difference in short-term outcomes of success rates using a transobturator or retropubic route. As shown by Richter at al, ${ }^{4}$ both the objective and subjective cure rates for the tension-free obturator sling (TOT) or retropubic tension-free vaginal sling (TVT) did not reach statistical significance.

Since that time, increasing trial data has emerged to allow us to draw the same conclusions regarding long-term outcomes of the retropubic and transobturator MUS and fascial slings. Depending on the definition used to define cure, the objective and subjective cure rates appear to be statistically similar with all sling modalities for the uncomplicated patient with stress incontinence. ${ }^{5-10}$

There does, however, appear to be a significant difference in complications between the approaches. The retropubic approach demonstrates an increased risk of intraoperative bladder perforations, de novo urgency and storage lower urinary tract symptoms (LUTS), while transobturator routes show an increased risk of vaginal erosion and groin pain. ,, $7-10^{-10}$

\section{Patient factors}

There has been a prevailing thought that common patient factors, such as obesity and older age, may influence the success of particular slings; however, recent data refutes that notion. 
Age of the patient does not appear to be a factor. ${ }^{11}$ Those over 70 vs. those of a younger age have shown no difference in incontinence cure rates regardless of which sling is used. Obesity also does not appear to alter the success rates of any of the slings, with published data demonstrating similar cure rates of incontinence in obese women for all sling types. ${ }^{12}$

The current literature is, however, quite clear that mesh for SUI needs to be avoided in certain patient populations. Synthetic mesh should be avoided in patients with prior urethral or vaginal erosion, urethral diverticulum (especially at the time of primary repair), prior urethrovaginal fistula, or prior urethral injury. For these patients, a facial pubovaginal sling should be the first choice. Data demonstrates better shortterm and long-term outcomes, as well as decreased patient morbidity with the fascial sling in these patient populations.

\section{Urethral or anatomical factors}

Hypermobility is one of the most common causes of SUI in women; however, there does not appear to be any statistically significant difference for the transobturator and retropubic MUS, or the pubovaginal sling in the treatment success rates for women with SUI secondary to urethral hypermobility. ${ }^{13}$

Intrinsic sphincter deficiency (ISD) is a troublesome problem for urological and gynecological surgeons who treat SUI in women. Multiple studies demonstrate a statistically significant difference in successful treatment favouring a retropubic sling (pubovaginal or TVT) vs. a transobturator approach for the treatment of SUI in women with ISD; ${ }^{14-16}$ however, even with a retropubic approach, the objective and subjective success rates in treating SUI fall well below what is seen with other diagnoses, such as urethral hypermobility. ${ }^{14-16}$

\section{Failure of primary sling}

When a sling fails to treat the SUI adequately (i.e., sling failure), very little published information exists regarding success rates for repeating the procedure with the same sling or changing to a different sling type. The limited information available does not favour any of the sling modalities. ${ }^{17}$

Published literature does demonstrate that the use of either a retropubic or transobturator approach regardless of the type of prior sling placed will likely yield comparable results for the second sling surgery. Again, however, the published literature is minimal on this topic. ${ }^{18}$ Some surgeons prefer the placement of a fascial pubovaginal sling in patients who have failed a prior synthetic MUS, although consistent data is lacking in the literature.

\section{Concurrent pelvic surgery}

Multivariate analysis suggests that there is minimal difference in SUI outcomes regardless of which sling (the tran- sobturator and retropubic MUS, or pubovaginal) is used. All have been reported to have excellent outcomes. ${ }^{19}$

\section{Practical tips}

Mesh slings should be used with caution in certain patient populations. Patient activities, such as horseback riding, may increase failure rates. In addition, many surgeons would suggest caution in placing slings in women with potential future pregnancy, high post-void residuals, and those using abdominal voiding to fully evacuate their bladders.

\section{Conclusion}

When considering which sling type to use for which incontinent woman, the published data demonstrates excellent results for both synthetic mesh (retropubic or transobturator routes) and fascial pubovaginal slings for most patients, except for the isolated indications discussed. Intrinsic sphincter deficiency does appear to be better treated with the use of a retropubic approach, although still with less than stellar results. Thus, for most patients, the treatment of incontinence may be solely based on which sling the surgeon feels most comfortable performing. Currently, most urologists and gynecologists favour synthetic MUS over fascial slings in surgicalnaïve patients; however, recent FDA warnings concerning the use of mesh in transvaginal surgery have patients questioning the safety of synthetic MUS for the treatment of SUI.

Competing interests: Dr. Steele has been an advisor for Allergan and Astellas; a speaker for Abbott and Astellas; has received grants from Astellas and Pfizer; and has participated in clinical trials supported by Astellas and Pfizer. Dr. Bailly has been an advisor and speaker for, has received honoraria from, and has participated in clinical trials supported by Allergan, Astellas, and Pfizer.

This paper has been peer reviewed.

\section{References}

1. Hampel C, Wienhold D, Benken N, et al. Definition of overactive bladder and epidemiology of urinary incontinence. Urology 1997;50:4-14; discussion 15-7. https://doi.org/10.1016/S00904295(97)00578-5

2. Wu J, Matthews $C A$, Conover MM, et al. Lifetime risk of stress urinary incontinence or pelvic organ prolapse surgery. Obstet Gynecol 2014;123:1201-6. https://doi.org/10.1097/AOG.0000000000000286

3. Nager C. Midurethral slings: Evidence-based vs. the medicolegal system. Am J Obstet Gynecol 2016;2014:708.el-5. https://doi.org/10.1016/i.ajog.2016.04.018

4. Richter HE, Albo ME, Zyczynski HM, et al. Retropubic vs. transobturator midurethral slings for stress incontinence. N Engl J Med 2010;362:2066-76. https://doi.org/10.1056/NEJMo00912658

5. Serati M, Braga A, Athanasiou $S$, et al. Tension-free vaginal tape-obturator for treatment of pure urodynamic stress urinary incontinence: Efficacy and adverse effects at 10 year followup. Eur Urol 2017;71:674-9. https://doi.org/10.1016/j.eururo.2016.08.054

6. Karmakar D, Mostafa A, Abdel-Fattah M. Long-term outcomes of transobturator tapes in women with stress urinary incontinence; E-TOTrandomized, controlled trial. BJOG 2017 Jan 17 [Epub ahead of print]. https://doi.org/10.1111/1471-0528.14561 
Steele et al.

7. Nilsson CG, Palva K, Rezapour $M$, et al. Eleven years' prospective followup of the tension-free vaginal tape procedure for treatment of stress urinary incontinence. Int Urogynecol J Pelvic Floor Dysfunct 2008;19:1043-7. htrps://doi.org/10.1007/s00192-008-0666-z

8. Brito LG, Rodrigues HL, Carvalho MA, et al. Comparison of the efficacy and safety of surgical procedures utilizing autologous fascial and transobturator slings in patients with stress urinary incontinence. J Reprod Med 2013;58:19-24.

9. Novara $G$, Artibani $W$, Barber MD et al. Updated systematic review and meta-analysis of the comparative data on colposuspensions, pubovaginal slings, and midurethral tapes in the surgical treatment of female stress urinary incontinence. Eur Urol 2010;58:218-38. https://doi.org/10.1016/i.eururo.2010.04.022

10. Laurikainen E, Valpas A, Kivelä A, et al. Retropubic compared with transobturator tape placement in treatment of urinary incontinence: A randomized, controlled trial. Obstet Gynecol 2007;109:4-11 https://doi.org/10.1097/01.A0G.0000249607.82768.al

11. Alas $A$, Chinthakanan 0 , Espaillat $L$, et al. Are suburethral slings less successful in the elderly? Int Urolgynecol J 2017;28:553-9. hittps://doi.org/10.1007/s00192-016-3132-3

12. Miranda V, Pineda R, Lovatsis $D$, et al. Efficacy and safety of tension-free vaginal tape compared with transobturator tape among obese women with stress urinary incontinence: A retrospective cohort study. J Obstet Gynaecol Can 2012;34:755-9. https://doi.org/10.1016/S1701-2163(16)35339-7

13. Cavkaytar S, Kokanalı MK, Guzel Al, et al. Comparison of TVT and TOT on urethral mobility and surgical outcomes in stress urinary incontinence with hypermobile urethra. Eur I Obstet Gynecol Reprod Biol 2015;190:36-40. https://doi.org/10.1016/i.ejogrb.2015.04.010
14. Jeon MJ, Jung HJ, Chung SM, et al. Comparison of the treatment outcome of pubovaginal sling, tensionfree vaginal tape and transobturator tape for stress urinary incontinence with intrinsic sphincter deficiency. Am J Obstet Gynecol 2008;199:76.el-4. https://doi.org/10.1016/i.ajog.2007.11.060

15. Ford A, Ogah J. Retropubic or transobturator midurethral slings for intrinsic sphincter deficiency-related stress urinary incontinence in women: A systematic review and meta-analysis. Int Urogynecol J 2016;27:19-28. https://doi.org/10.1007/s00192-015-2797-3

16. Schierlitz L, Dwyer PL, Rosamilia A, et al. Effectiveness of tension-free vaginal tape compared with transobturator tape in women with stress urinary incontinence and intrinsic sphincter deficiency: A randomized, controlled trial. Obstet Gynecol 2008; 112:1253-61. https://doi.org/10.1097/AOG.0b013e31818db391

17. Ulrich D, Bijelic-Radisic V, Grabner K, et al. Objective outcome and quality-of-life assessment in women with repeat incontinence surgery. Neurorol Urodyn 2016 Sep 27 [Epub ahead of print].

18. Verbrugghe A, De Ridder D, Van der Aa F. A repeat midurethral sling as valuable treatment for persistent or recurrent stress urinary incontinence. Int Urogynecol J 2013;24:999-1004. htrps://doi.org/10.1007/ s00192-012-1971-0

19. Rapp DE, Dolat ME, Wiley J, et al. Effect of concurrent prolapse surgery on stress urinary incontinence outcomes after TVTO. Female Pelvic Med Reconstr Surg 2017 Jan 18 [Epub ahead of print]. https://doi.org/10.1097/SPV.0000000000000364

Correspondence: Dr. Stephen S. Steele, Queen's University, Kingston, ON, Canada; steeles@kgh.kari.net 